\title{
ДИНАМИКА ФОТОСИНТЕТИЧЕСКИХ ПРОЦЕССОВ В УСЛОВИЯХ ПЕРЕМЕННОГО СПЕКТРАЛЬНОГО ОБЛУЧЕНИЯ РАСТЕНИЙ
}

\author{
Ю.Ц. МАРТИРОСЯН ${ }^{1,2}$, Л.Ю. МАРТИРОСЯН ${ }^{1,2}$, А.А. КОСОБРЮХОВ1, 3
}

В естественных условиях, наряду с изменениями интенсивности света в различные промежутки времени, меняется спектральный состав падающей радиации. Соотношение между синей и красной спектральными областями колеблется от $\approx 0,5$ (прямое излучение солнца) до $\approx 0,95$ (диффузное солнечное излучение) в зависимости от высоты стояния солнца и времени суток. В настоящей работе мы впервые определили особенности влияния синего и красного участков спектра на фоне облучения растений всей областью фотосинтетически активной радиации (ФАР) на активность первичных процессов и скорость фотосинтеза. Целью работы было определение активности фотосинтетического аппарата листьев картофеля в условиях длительного действия на растения света разного спектрального состава, а также в динамике при изменении спектра с преобладающим красным (ФАР + КС) или синим (ФАР + СС) облучением. Растения картофеля (Solanum tuberosum L.) сорта Жуковский ранний выращивали методом аэропоники в двух камерах фитотрона с преимущественным облучением растений светодиодами синего $\left(\lambda_{\max }=470\right.$ нм, СД СС) или красного света $\left(\lambda_{\max }=660\right.$ нм, СД КС) в области ФАР. В одной камере доля синего света при общей интенсивности облучения ФАР $400 \pm 28$ мкмоль $\cdot \mathrm{M}^{-2} \cdot \mathrm{c}^{-1}$ составляла 293,6 мкмоль $\cdot \mathrm{M}^{-2} \cdot \mathrm{c}^{-1}$, в другой доля красного света $-262,0$ мкмоль $\mathrm{m}^{-2} \cdot \mathrm{c}^{-1}$. Измерения проводили на растениях, длительно выращиваемых при облучении ФАР + СС или ФАР + КС. Определяли зависимость скорости фотосинтеза при облученности 400 мкмоль $\mathrm{m}^{-2} \cdot \mathrm{c}^{-1}$, а также в диапазоне от 0 до 1200 мкмоль $\cdot \mathrm{m}^{-2} \cdot \mathrm{c}^{-1}$, последовательно повышая интенсивность света (световые кривые). Исследовали динамику фотосинтетических показателей в течение 3 ч при смене светового режима выращивания с ФАР + КС на ФАР + СС или с ФАР + СС на ФАР + КС. При облучении растений ФАР + КС была отмечена менышая скорость фотосинтеза по сравнению с показателями у растений, выращенных в условиях ФАР + СС как при 400 мкмоль $\mathrm{м}^{-2} \cdot \mathrm{c}^{-1}$, так и при высокой облученности 1200 мкмоль $\mathrm{m}^{-2} \cdot \mathrm{c}^{-1}$. Изменение спектрального режима с ФАР + КС на ФАР + СС приводило к увеличению скорости фотосинтеза, некоторому повышению эффективного квантового выхода и усилению нефотохимического тушения. При изменении светового режима с ФАР + СС на ФАР + КС снижались скорость фотосинтеза, скорость электронного транспорта и нефотохимического тушения по сравнению с показателями у растений, облучаемых ФАР + СС, но не наблюдалось изменений максимального и эффективного квантового выхода. Выявленные нами закономерности дают возможность лучше понять механизмы приспособления растений в естественных условиях произрастания, а при применении светокультуры целевым образом использовать светодиодные источники различного спектрального состава с учетом времени действия синей или красной составляющей спектра облучения.

Ключевые слова: спектральный режим, фотосинтетический аппарат, скорость фотосинтеза, электронный транспорт, нефотохимическое тушение, светодиоды, Solanum tuberosum L., картофель.

Интенсивность и спектральный состав света - важные факторы регуляции активности фотосинтетического аппарата, роста и развития растений $(1,2)$. В естественных условиях произрастания наряду с колебаниями интенсивности света в течение различных промежутков времени изменяется спектральный состав падающей радиации. Так, в дневные часы энергия в синей (СС, $\lambda=400-500$ нм) и красной (KC, $\lambda=600-700$ нм) областях спектра распределяется в соотношении 1:3 (3). В утренние и вечерние часы повышается доля красной и дальней красной компонент по сравнению с синей и величина СС/КС составляет 0,74. По данным ряда работ (46), пропорция между энергией синей и красной спектральных областей варьирует от $\approx 0,50$ (прямое излучение) до $\approx 0,95$ (диффузное излучение) в зависимости от высоты стояния солнца.

Световые режимы, влияющие на фотосинтетическую активность, существенные элементы технологий в условиях светокультуры и контро-

* Работа выполнена в рамках государственного задания № 0574-2014-0009. 
лируемого выращивания растений в фитотронах различного типа. При этом активно используются источники на основе светодиодных облучателей (СД). Наиболее широко распространены белые СД (7) совместно с красными и красно-синими $(8,9)$, а также с различным соотношением синей, красной и других спектральных областей (10-12). В зависимости от вида растений их реакция на соотношение $\mathrm{KC}$ и СС может быть неодинаковой (2). Также отмечается необходимость изменения соотношения $\mathrm{KC} / \mathrm{CC}$ в онтогенезе (13).

В настоящее время одним из основных подходов при исследовании приспособления растений к изменяющимся условиям внешней среды служит сопоставление динамических характеристик адаптационных процессов $(14,15)$. При этом существенное внимание уделяется действию и последействию различных факторов в часовых временных интервалах (16, 17). Такой подход позволяет оценить характер ответной реакции фотосинтетического аппарата в динамике, приближенной к естественному изменению факторов среды, на протяжении нескольких часов. Следует отметить, что механизмы световой адаптации растений сложны и требуют дальнейшего детального изучения, в том числе для оптимизации целевого использования светодиодных источников разного спектрального состава в светокультуре.

Ранее мы изучили влияние длительного воздействия монохроматических спектральных источников облучения на растения картофеля в культуре in vitro (18) и обнаружили, что при низкой интенсивности света не наблюдается значительных различий в активности световых реакций фотосинтеза. При этом изменения в накоплении сухого вещества растениями были обусловлены проводимостью устьиц, а также процессами, связанными с реакциями темновой фазы фотосинтеза, - эффективностью реакции карбоксилирования, скоростью утилизации триозофосфатов.

В представленном исследовании нами впервые показано, что особенность влияния синего и красного участков спектра на фоне облучения растений всей областью фотосинтетически активной радиации (ФАР) заключается в том, что смена красного света на синий приводит к повышению скорости фотосинтеза, эффективного квантового выхода и усилению нефотохимического тушения, тогда как при замене синего света красным наблюдаются обратные эффекты.

Целью работы было определение активности фотосинтетического аппарата листьев картофеля в условиях длительного действия на растения света разного спектрального состава, а также в динамике, при изменении спектра облучения с преобладанием красной или синей области.

Методика. Растения картофеля (Solanum tuberosum L.) сорта Жуковский ранний выращивали методом аэропоники в двух камерах фитотрона с контролируемыми условиями среды. Растения получали методом апикальных меристем и тестировали на отсутствие вирусов и вироида картофеля методом ОТ-ПЦР в реальном времени с применением соответствующих наборов (ООО НПК «Синтол», Россия). В каждую камеру высаживали по 15 растений. Длительность их вегетационного периода составляла 60 сут, фотопериод -12 ч.

В камере № 1 увеличивали интенсивность облучения синими светодиодами $\left(\lambda_{\max }=470\right.$ нм, СД СС) и выключали светодиоды красного цвета, в результате при общей интенсивности $400 \pm 28 \_$мкмоль $\cdot \mathrm{M}^{-2} \cdot \mathrm{c}^{-1}$ на СС приходилось 293,6 мкмоль м $^{-2} \cdot \mathrm{c}^{-1}$. В камере № 2 повышали интенсивность облучения красным светом $\left(\lambda_{\max }=660\right.$ нм, СД КС) при отключенных синих светодиодах, при этом доля КС составляла 262,0 мкмоль $\cdot \mathrm{M}^{-2} \cdot \mathrm{c}^{-1}$, общая интенсивность облучения - $400 \pm 28$ мкмоль $\cdot \mathrm{M}^{-2} \cdot \mathrm{c}^{-1}$. Величина $\mathrm{CC} / \mathrm{KC}$ 
(при сравнении интенсивности облучения в двух камерах фитотрона) - в пределах 0,7-09. Другие микроклиматические условия внутри камер поддерживали постоянными (концентрация $\mathrm{CO}_{2}-395 \pm 12$ мкмоль $\mathrm{CO}_{2} \cdot$ моль $^{-1}$, влажность воздуха $-60-80 \%$, температура $\left.-24 \pm 1{ }^{\circ} \mathrm{C}\right)$.

Измерения анализируемых показателей проводили на длительно выращиваемых растениях в динамике (0, 1-й, 2-й, 3-й ч) в двух вариантах: при стационарном световом режиме с преобладающим синим (ФАР + СС) или красным (ФАР + КС) светом и после замещения одного преобладающего света другим (смена режима с ФАР + КС на ФАР + СС или с ФАР + СС на ФАР + KC).

Скорость фотосинтеза в листьях регистрировали в утреннее время (в $10^{00}$ ) при интенсивности света 400 и 1200 мкмоль $\cdot \mathrm{M}^{-2} \cdot \mathrm{c}^{-1}$. Определяли зависимость скорости процесса от интенсивности света (световые кривые фотосинтеза) в диапазоне ФАР от 0 до 1200 мкмоль $\cdot \mathrm{M}^{-2} \cdot \mathrm{c}^{-1}$ при естественной концентрации $\mathrm{CO}_{2}$ в воздухе $395 \pm 12$ мкмоль $\mathrm{CO}_{2} \cdot$ моль ${ }^{-1}$. Одновременно оценивали параметры переменной флуоресценции хлорофилла a, характеризующие активность фотосистемы II (ФС II) (19).

Скорость фотосинтеза измеряли портативным газоанализатором LCPro+ («ADC BioScientific, Ltd», Великобритания), переменную флуоресценцию - флуориметром PAM-Jnior («Heinz Walz GmbH», Германия). Спектральные параметры в камерах фитотрона контролировали с помощью с помощью спектрометров ASENSEtek, PG100N, UPRtek (Тайвань). Световую кривую аппроксимировали моделью J.L. Prioul и P. Chartier (20).

Эксперименты выполняли в 4-5-кратной аналитической и 3-кратной биологической повторности. Расчеты осуществляли по данным одного биологического опыта. Статистическую обработку проводили в программе Statistica 10 («StatSoft, Inc.», США) На рисунках приведены средние арифметические значения $(M)$ со стандартной ошибкой $( \pm \mathrm{SEM})$. Достоверность различий определяли по $t$-критерию Стьюдента при $\mathrm{P}=0,95$.

Результаты. Выращивание растений в условиях полного спектра ФАР с преобладающим красным или синим облучением (рис. 1) приводило к изменению морфологических параметров. При ФАР + СС растения имели укороченные междоузлия и развитую корневую систему, в условиях ФАР + КС - были выше, с менее развитой корневой системой. Наблюдаемые изменения ростовых показателей связаны с функциональной активностью фотосинтетического аппарата.

При ФАР + КС по сравнению с ФАР + СС скорость фотосинтеза была меньшей как при 400 мкмоль $\cdot \mathrm{M}^{-2} \cdot \mathrm{c}^{-1}$, так и при 1200 мкмоль $\cdot \mathrm{M}^{-2} \cdot \mathrm{c}^{-1}$ (рис. 2). Изменение режима с ФАР + КС на ФАР + СС приводило к повышению скорости фотосинтеза при 400 мкмоль $\cdot \mathrm{M}^{-2} \cdot \mathrm{c}^{-1}$ и некоторому увеличению - при 1200 мкмоль $\cdot \mathrm{M}^{-2} \cdot \mathrm{c}^{-1}$. При изменении светового режима с ФАР + СС на ФАР + КС при 400 мкмоль $\cdot \mathrm{M}^{-2} \cdot \mathrm{c}^{-1}$ этот показатель снижался $(\mathrm{p} \leq 0,05)$.

Наряду с исследованием длительного воздействия света ФАР + КС и ФАР + СС на активность фотосинтетического аппарата были построены световые кривые фотосинтеза растений при смене спектрального режима облучения. Изменение светового режима с ФАР + КС на ФАР + СС приводило к повышению скорости фотосинтеза на плато световой кривой, увеличению скорости дыхания и квантового выхода, при этом насыщение световой кривой фотосинтеза достигалось при большей интенсивности света. При последовательности режимов ФАР + КС $\rightarrow$ ФА + СС, напротив, скорость фотосинтеза, дыхания и квантовый выход снижались, а насыщение световой кривой происходило при меньшей интенсивности света (рис. 3). 


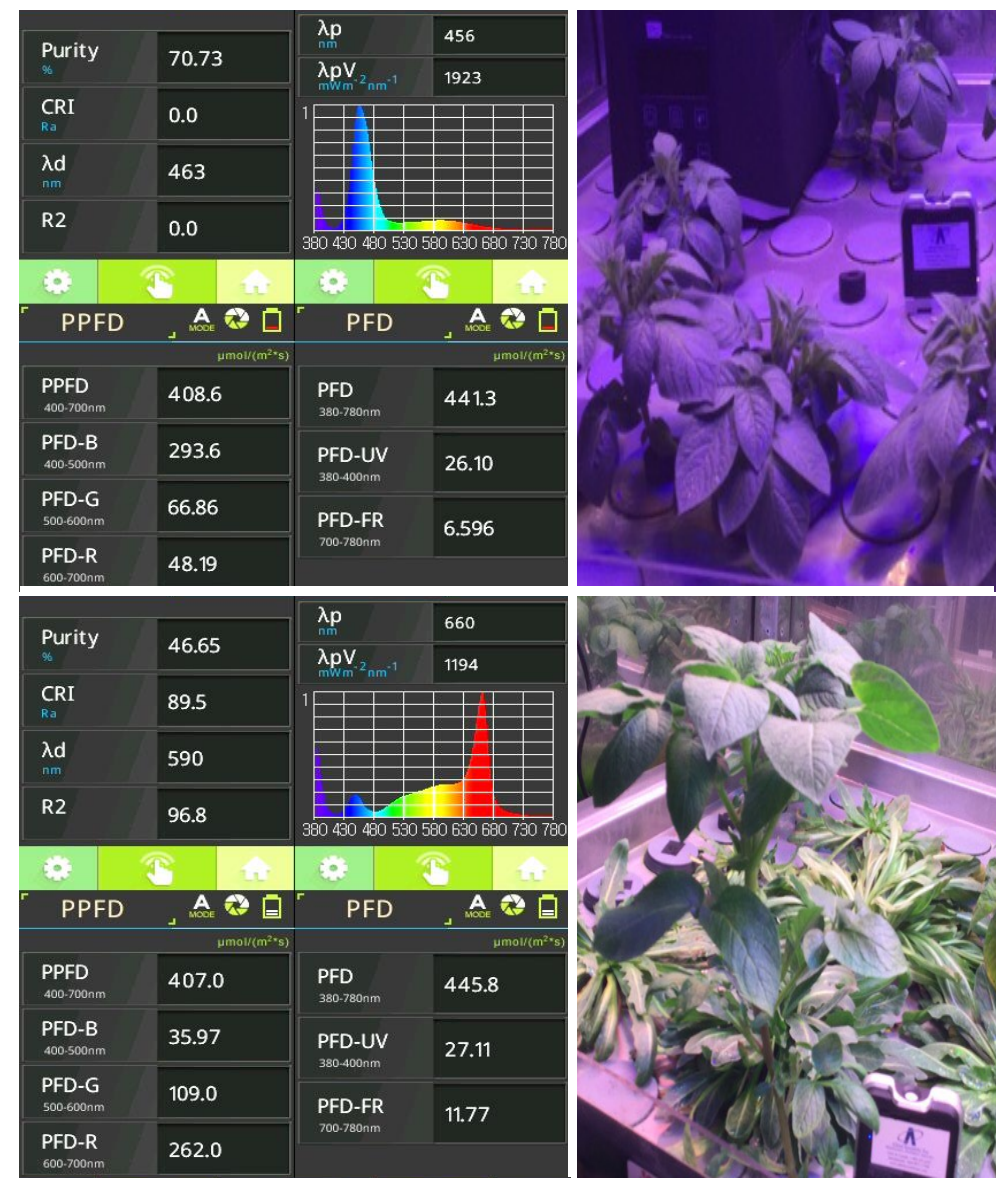

Рис. 1. Спектральные характеристики камер фитотрона. ФАР + СС (синий свет, вверху): общий поток фотонов $-408,6$ мкмоль $\cdot \mathrm{M}^{-2} \cdot \mathrm{c}^{-1}$, синий и красный участки спектра - соответственно 293,6 и 48,19 мкмоль $\cdot \mathrm{M}^{-2} \cdot \mathrm{c}^{-1}$; ФАР + КС (красный свет, внизу): общий поток $-407,0$, красный и синий участки спектра - соответственно 262,0 и 35,97 мкмоль $\cdot \mathrm{M}^{-2} \cdot \mathrm{c}^{-1}$.

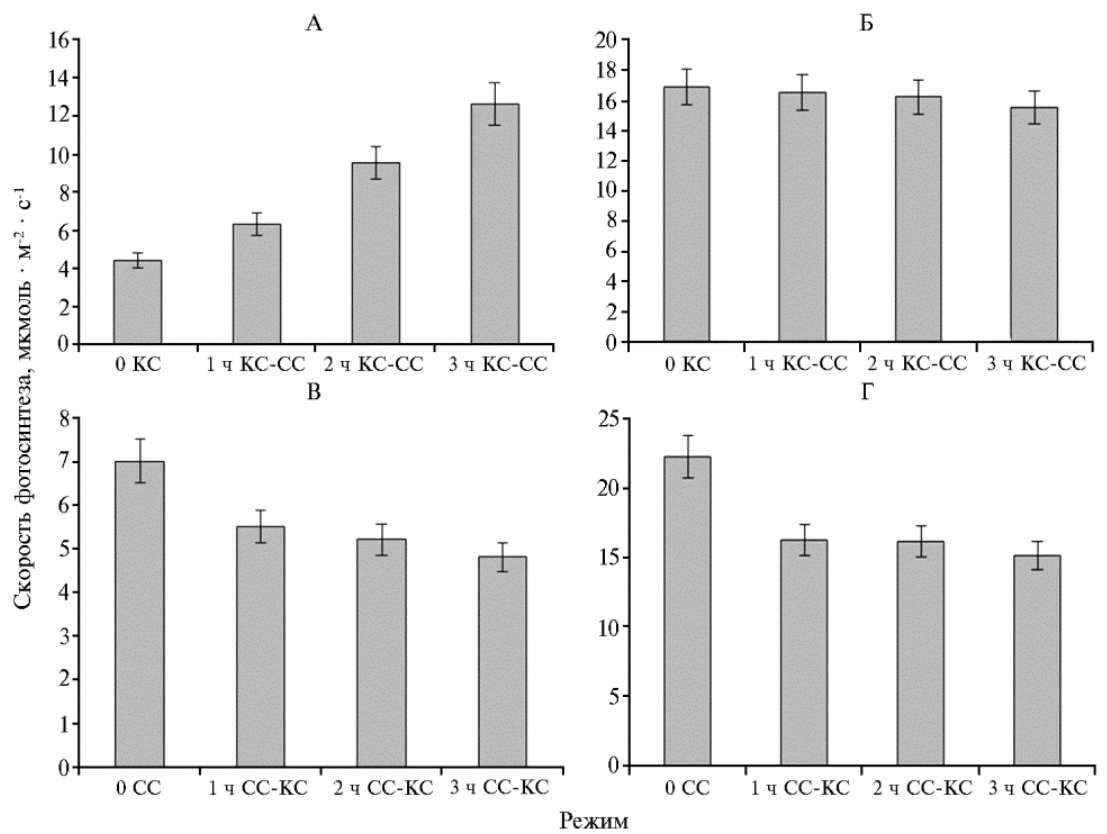

Рис. 2. Динамика $\mathrm{CO}_{2}$-газообмена в листьях растений картофеля (Solanum tuberosum L.) сорта 
Жуковский ранний, длительно выращиваемых в условиях аэропоники при интенсивности света 400 мкмоль $\cdot \mathbf{m}^{-2} \cdot \mathrm{c}^{-1}$ с преобладанием красного $(\mathrm{KC}$, ФАР $+\mathrm{KC})$ или синего $(\mathrm{CC}$, ФАР + СС) света, после замещения одного преобладающего света другим (КС-СС или СС-КС): А, В - без изменения интенсивности света (400 мкмоль $\left.\cdot \mathrm{M}^{-2} \cdot \mathrm{c}^{-1}\right)$, Б, Г - при повышении интенсивности света до 1200 мкмоль $\cdot \mathrm{M}^{-2} \cdot \mathrm{c}^{-1}$; ФАР - фотосинтетически активная радиация.
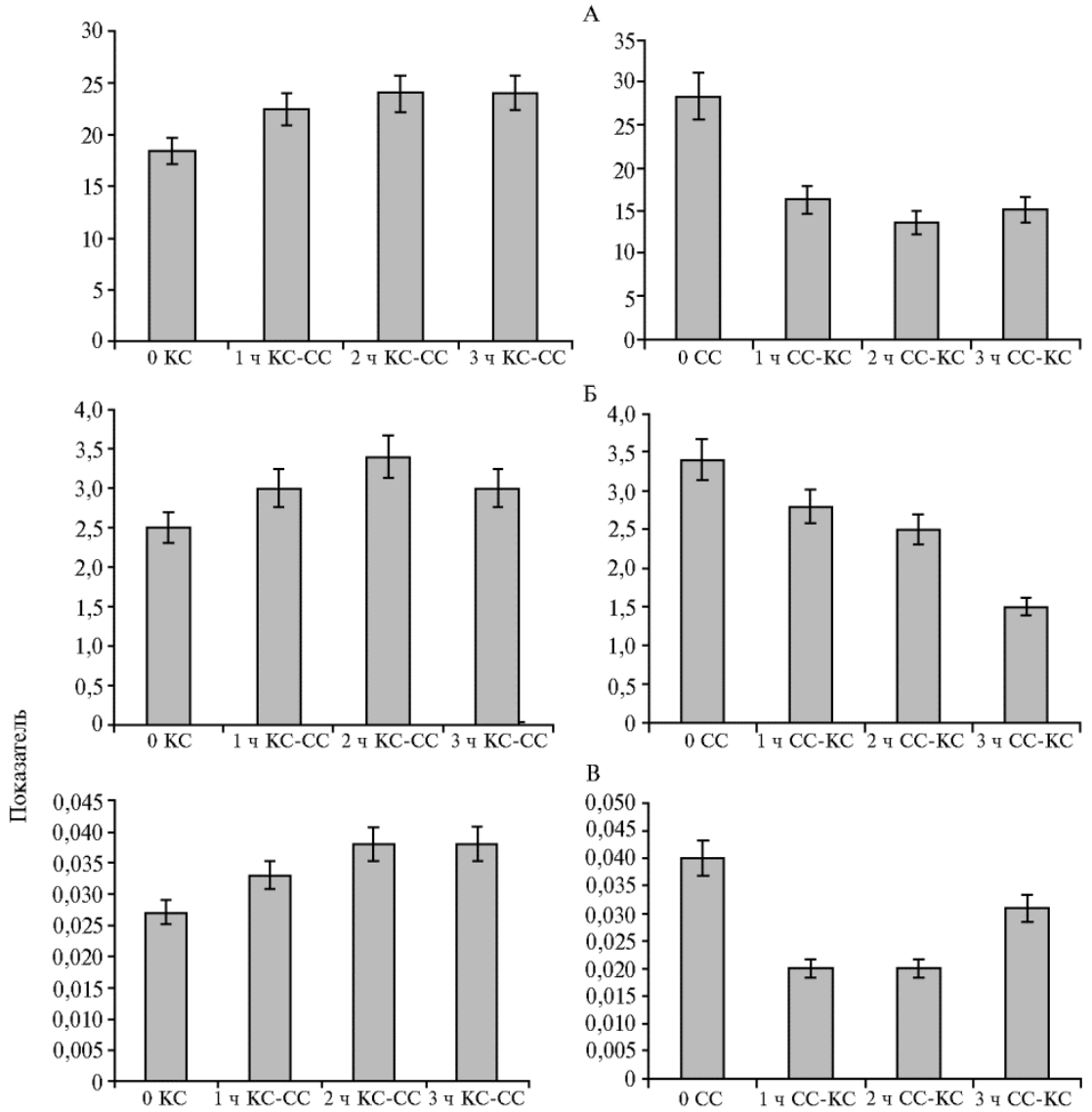

Б

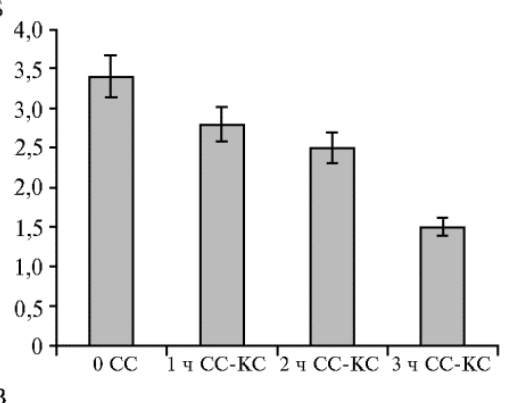

0,050

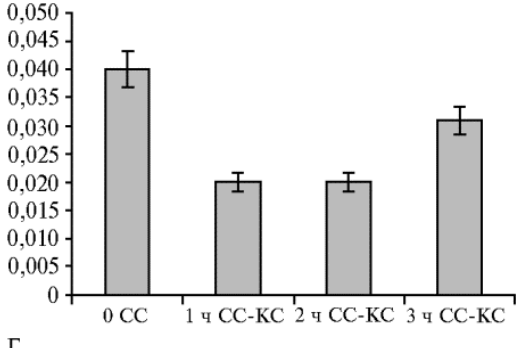

г
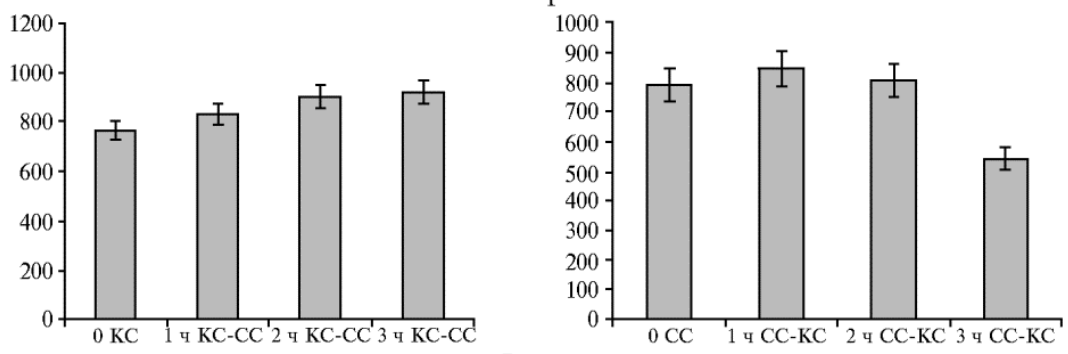

Режим

Рис. 3. Динамика скорости поглощения $\mathrm{CO}_{2}$, мкмоль $\cdot \mathrm{M}^{-2} \cdot \mathrm{c}^{-1}(\mathrm{~A})$, скорости дыхания, мкмоль $\cdot \mathrm{M}^{-2} \cdot \mathrm{c}^{-1}$ (Б), квантовая эффективность фотосинтеза, отн. ед. (В) и интенсивность света на плато световой кривой, мкмоль $\cdot \mathrm{м}^{-2} \cdot \mathrm{c}^{-1}(\Gamma)$ у растений картофеля (Solanum tuberosum L.) сорта Жуковский ранний, длительно выращиваемых в условиях аэропоники при интенсивности света 400 мкмоль $\cdot \mathrm{m}^{-2} \cdot \mathrm{c}^{-1} \mathrm{c}$ преобладанием красного (КС, ФАР + КС) или синего (СС, ФАР + СС) света, после замещения одного преобладающего света другим (КС-СС или СС-КС; ФАР - фотосинтетически активная радиация).

Наблюдаемые изменения скорости фотосинтеза связаны, в частности, с неодинаковой активностью реакций на его световой стадии. Анализ параметров переменной флуоресценции показал, что смена преимущественно красного света на синий не повлияла на величину максимального квантового выхода ФС II, но способствовала повышению скорости нефото- 

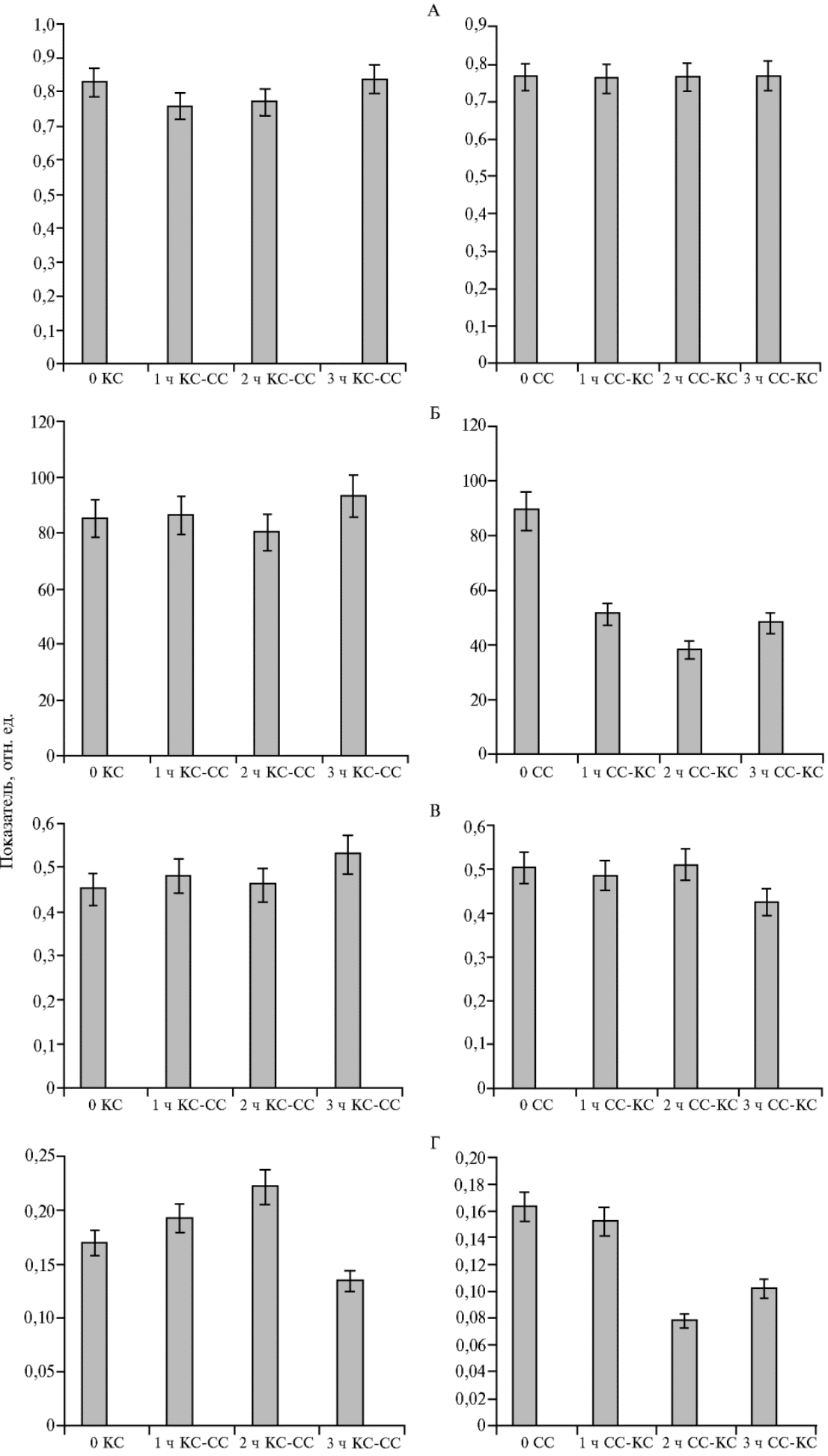

$\Gamma$

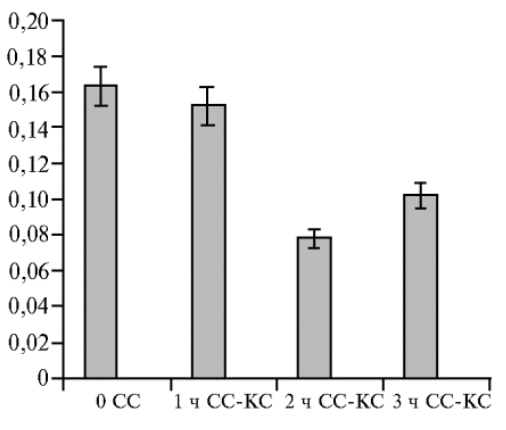

Рис. 4. Максимальный квантовый выход фотосистемы II (А), эффективный квантовый выход фотосистемы II (Б), скорость электронного транспорта (В) и скорость нефотохимического тушения (Г) у растений картофеля (Solanum tuberosum L.) сорта Жуковский ранний, длительно выращиваемых в условиях аэропоники при интенсивности света 400 мкмоль $\cdot \mathrm{m}^{-2} \cdot \mathrm{c}^{-1}$ с преобладанием красного (КС, ФАР + КС) или синего $(\mathrm{CC}$, ФАР + СС) света, после замещения одного преобладающего света другим (КС-СС или СС-КС; ФАР - фотосинтетически активная радиация). 
химического тушения и эффективного квантового выхода (p $\leq 0,05)$ (рис. 4). Противоположную реакцию фотосинтетического аппарата (снижение скорости электронного транспорта и нефотохимического тушения) отмечали при смене режима с ФАР + СС на ФАР + КС. Показатели максимального и эффективного квантовых выходов по сравнению с таковыми у растений, облучаемыми СД синего света, сохранялись прежними (см. рис. 4).

Влияние света ФАР + КС и ФАР + СС на скорость фотосинтеза, наблюдаемое в наших экспериментах, сопоставимо с данными о снижении активности фотосинтетического аппарата при облучении растений монохроматическим $\mathrm{KC}(21,22)$. Отмеченное нами увеличение доли красной или синей составляющей в спектре ФАР не приводило к изменениям максимального (см. рис. 3, А) и эффективного (см. рис. 4, Б) квантового выхода фотосинтеза, скорости электронного транспорта (см. рис. 4, В), а также скорости нефотохимического тушения (см. рис. 4, Г). В этом случае меньшая скорость фотосинтеза при облучении ФАР + КС может быть обусловлена более низкой активностью карбоксилирующего фермента Рубиско (RuBisCO), что показано в работе А.А. Тихомирова с соавт. (2) и в наших исследованиях по действию монохроматического облучения на растения картофеля (18). Снижение скорости нефотохимического тушения флуоресценции (NPQ) через 3 ч облучения растений ФАР + CC также может свидетельствовать о повышении эффективности использования синего света в ассимиляционных процессах, даже при низкой величине отношения CC/KC. M. Kośvancová-Zitová c coaвт. (23) отмечали высокую скорость индукции фотосинтеза при соотношении $\mathrm{CC} / \mathrm{KC}$, равном 3:1. Уменьшение соотношения синего $\left(\lambda_{\max }=455\right.$ нм) и красного $\left(\lambda_{\max }=625\right.$ нм$)$ света не дало различий в индукции фотосинтеза в листьях, получающих СС и КС в равных пропорциях (1:1) и при снижении доли СС относительно КС (1:3). Значительные изменения в скорости фотосинтеза наблюдались при смене светового режима выращивания. Так, 2-3-кратное повышение происходило при замещении ФАР + КС на ФАР + СС в течение 3 ч (см. рис. 2, А, В). В этих же условиях отмечались более высокие значения квантового выхода фотосинтеза (см. рис. 3, В). При световом насыщении (1200 мкмоль $\left.\cdot \mathrm{M}^{-2} \cdot \mathrm{c}^{-1}\right)$ скорость фотосинтеза практически не изменялась (см. рис. 2, Б, Г), что указывает на высокий функциональный потенциал фотосинтетического аппарата, сформированного растением при большей доле красного света в общем потоке облучения. При этом через 1 ч после изменения светового режима не отмечали кардинальных сдвигов в активности фотосинтетического аппарата.

Изменение светового режима с ФАР + СС на ФАР + КС приводило к снижению скорости фотосинтеза при 400 и 1200 мкмоль $\cdot \mathrm{M}^{-2} \cdot \mathrm{c}^{-1}$ (см. рис. 2), а также к уменышению скорости темнового дыхания, интенсивности света при насыщении световой кривой, квантового выхода фотосинтеза (см. рис. 3). Наблюдаемые изменения активности фотосинтетического аппарата были связаны также с реакциями световой стадии фотосинтеза замедлением работы электрон-транспортной цепи хлоропластов (см. рис. 4, В). Уменьшение скорости электронного транспорта и, как следствие, синтеза АТФ (24) может сопровождаться снижением активности Рубиско (25). В этом случае сокращение непроизводительных потерь энергии (NPQ) способно нивелировать эффект изменения активности реакций первичной стадии фотосинтеза.

Спектральное распределение света в источниках облучения влияет на скорость фотосинтеза не только непосредственно, но и косвенно - через наложение эффектов от разных участков спектра. Лист регулирует ба- 
ланс распределения энергии возбуждения между фотосистемами в ответ на относительное спектральное распределение света (26). В результате облучение растений светом с большей или меньшей долей синей или красной составляющей спектра на фоне всей области ФАР неодинаково сказывалось на скорости реакций световой и темновой стадий фотосинтеза.

Таким образом, показано, что смена преимущественно красного света на преимущественно синий в светокультуре приводит к повышению скорости фотосинтеза, эффективного квантового выхода и усилению нефотохимического тушения, тогда как при замене синего света красным эффекты обратные. Выявленные особенности действия синего и красного участков спектра на активность реакций световой стадии фотосинтеза и скорость фотосинтеза при длительном действии светового фактора на растения и при изменении спектрального состава облучения позволяет лучше понять характер реакции растений на факторы среды при естественных условиях произрастания. Полученные результаты также могут быть использованы при программированном выращивании растений в культивационных сооружениях различного типа.

\section{ЛИТЕРАТУРА}

1. Воскресенская Н.П. Принципы регулирования метаболизма растений и регуляторное действие красного и синего света на фотосинтез. В кн.: Фоторегуляция метаболизма $u$ морфогенеза растений. М., 1975: 16-36.

2. Тихомиров А.А., Шарупич В.П., Лисовский Г.М. Светокультура растений: биофизические и биотехнологические основы. Новосибирск, 2000.

3. Шульгин И.А. Растение и солнце. Л., 1973.

4. Grant R.H. Partitioning of biologically active radiation in plant canopies. Int. J. Biometeorol., 1997, 40(1): 26-40 (doi: 10.1007/BF02439408).

5. Navrátil M., Špunda V., Marková I., Janouš D. Spectral composition of photosynthetically active radiation penetrating into a Norway spruce canopy: the opposite dynamics of the blue/red spectral ratio during clear and overcast days. Trees, 2007, 21(3): 311-320 (doi: 10.1007/s00468007-0124-4).

6. Urban O., Janouš D., Acosta M., Czerný R., Marková I., Navrátil M., Pavelka M., Pokorný R., Šprtová M., Zhang R., Špunda V., Grace J., Marek M.V. Ecophysiological controls over the net ecosystem exchange of mountain spruce stand. Comparison of the response in direct vs. diffuse solar radiation. Glob. Change Biol., 2007, 13(1): 157-168 (doi: 10.1111/j.1365-2486.2006.01265.x).

7. Cope K., Bugbee B. Spectral effects of three types of white light-emitting diodes on plant growth and development: absolute versus relative amounts of blue light. HortScience, 2013, 48(4): 504-509 (doi: 10.21273/HORTSCI.48.4.504).

8. Dong C., Fu Y., Liu G., Liu H. Growth, photosynthetic characteristics, antioxidant capacity and biomass yield and quality of wheat (Triticum aestivum L.) exposed to LED light sources with different spectra combinations. J. Agron. Crop Sci., 2014, 200(3): 219-230 (doi: 10.1111/jac.12059).

9. Kang J.-H., Krishna Kumar S., Atulba S.L.S., Jeong B.R., Hwang S.J. Light intensity and photoperiod influence the growth and development of hydroponically grown leaf lettuce in a closed-type plant factory system. Hortic. Environ. Biotechnol., 2013, 54(6): 501-509 (doi: 10.1007/s13580-013-0109-8).

10. Su N., Wu Q., Shen Z., Xia K., Cui J. Effects of light quality on the chloroplastic ultrastructure and photosynthetic characteristics of cucumber seedlings. Plant Growth Regulation, 2014, 73(3): 227-235 (doi: 10.1007/s10725-013-9883-7).

11. Wu Q., Su N., Shen W., Cui J. Analyzing photosynthetic activity and growth of Solanum lycopersicum seedlings exposed to different light qualities. Acta Physiologiae Plantarum, 2014, 36(6): 1411-1420 (doi: 10.1007/s11738-014-1519-7).

12. Lina K.H., Huang M.Y., Huangc W.D., Hsuc M.H., Yangd Z.W., Yang C.M. The effects of red, blue, and white light-emitting diodes on the growth, development, and edible quality of hydroponically grown lettuce (Lactuca sativa L. var. capitata). Scientia Horticulturae, 2013, 150: 86-91 (doi: 10.1016/j.scienta.2012.10.002).

13. Мартиросян Ю.Ц., Полякова М.Н., Диловарова Т.А., Кособрюхов А.А. Фотосинтез и продуктивность растений картофеля в условиях различного спектрального облучения. Сельскохозяйственная биология, 2013, 1: 107-112. 
14. Urban O., Šprtová M., Košvancová M., Tomášková I., Lichtenthaler H.K., Marek M.V. Comparison of photosynthetic induction and transient limitations during the induction phase in young and mature leaves from three poplar clones. Tree Physiology, 2008, 28(8): 1189-1197 (doi: 10.1093/treephys/28.8.1189).

15. Montgomery R.A., Givnish T.J. Adaptive radiation of photosynthetic physiology in the Hawaiian lobeliads: dynamic photosynthetic responses. Oecologia, 2008, 155(3): 455-467 (doi: 10.1007/s00442-007-0936-3).

16. Кособрюхов А.А. Активность фотосинтетического аппарата при периодическом повышении концентрации $\mathrm{CO}_{2}$. Физиология растений, 2009, 56(1): 8-16.

17. Марковская Е.Ф., Сысоева М.И. Роль суточного температурного градиента в онтогенезе растений. М., 2004.

18. Мартиросян Ю.Ц., Диловарова Т.А., Мартиросян В.В., Креславский В.Д., Кособрюхов А.А. Действие светодиодного облучения различного спектрального состава на фотосинтетический аппарат растений картофеля в культуре in vitro. Сельскохозяйственная биология, 2016, 51(5): 680-687 (doi: 10.15389/agrobiology.2016.5.680rus).

19. Гольцев В.Н., Каладжи Х.М., Кузманова М.А., Аллахвердиев С.И. Переменная и замедленная флуоресценция хлорофилла а - теоретические основы и практическое приложение в исследовании растений. Ижевск-М., 2014.

20. Prioul J.L., Chartier P. Partitioning of transfer and carboxylation components of intracellular resistance to photosynthetic $\mathrm{CO}_{2}$ fixation: a critical analysis of the methods used. Annals of Botany, 1977, 41(4): 789-800 (doi: 10.1093/oxfordjournals.aob.a085354)

21. Aksenova N.P., Konstantinova T.N., Sergeeva L.I., Machackova I., Golyanovskaya S.A. Morphogenesis of potato plants in vitro. I. Effect of light quality and hormones. J. Plant Growth Regul., 1994, 13(3): 143-146 (doi: 10.1007/BF00196378).

22. Matsuda R., Ohashi-Kaneko K., Fujiwara K., Goto E., Kurata K. Photosynthetic characteristics of rice leaves grown under red light with or without supplemental blue light. Plant Cell Physiol., 2004, 45(12): 1870-1874 (doi: 10.1093/pcp/pch203).

23. Kośvancová-Zitová M., Urban O., Navrátil M., Špunda V., Robson T.M., Marek M.V. Blue radiation stimulates photosynthetic induction in Fagus sylvatica L. Photosynthetica, 2009, 47(3): 388-398 (doi: 10.1007/s11099-009-0060-1).

24. Foyer C., Furbank R., Harbinson J., Horton P. The mechanisms contributing to photosynthetic control of electron transport by carbon assimilation in leaves. Photosynth. Res., 1990, 25(2): 83100 (doi: 10.1007/BF00035457).

25. Farquhar G.D., von Caemmerer S., Berry J.A. A biochemical model of photosynthetic $\mathrm{CO}_{2}$ assimilation in leaves of C3 plants. Planta, 1980, 149: 78-90 (doi: 10.1007/BF00386231).

26. Murakami K., Matsuda R., Fujiwara K. A basis for selecting light spectral distribution for evaluating leaf photosynthetic rates of plants grown under different light spectral distributions. Environmental Control in Biology, 2017, 55(1): 1-6 (doi: 10.2525/ecb.55.1).

\title{
1 ІФБНУ Всероссийский НИИ сельскохозяйственной Поступила в редакцию биотехнологии, 8 октября 2018 года
}

127550 Россия, г. Москва, ул. Тимирязевская, 42,

e-mail: yumart@yandex.ru $\triangle$

2ФГБУН Институт биохимической физики

им. Н.М. Эмануэля РАН,

119334 Россия, г. Москва, ул. Косыгина, 4,

e-mail: yumart@yandex.ru;

ЗФГБУН Институт фундаментальных проблем

биологии РАН,

142290 Россия, Московская обл., г. Пушино, ул. Институтская, 2,

e-mail: kosobr@rambler.ru

Sel'skokhozyaistvennaya biologiya [Agricultural Biology], 2019, V. 54, № 1, pp. 130-139

\section{DYNAMIC REGULATION OF PHOTOSYNTHETIC PROCESSES UNDER VARIABLE SPECTRAL LED IRRADIATION OF PLANTS}

\author{
Yu.Ts. Martirosyan1, 2, L.Yu. Martirosyan 1, 2, A.A. Kosobryukhov1, 3
}

${ }^{1}$ All-Russian Research Institute of Agricultural Biotechnology, 42, ul. Timiryazevskaya, Moscow, 127550 Russia, e-mail yumart@yandex.ru ( $\square$ corresponding author);

${ }^{2}$ Emanuel Institute of Biochemical Physics RAS, 4, ul. Kosygina, Moscow, 119991 Russia, e-mail yumart@yandex.ru;

3 Institute of Basic Biological Problems, 2, ul. Institutskaya, Pushchino, Moscow Province, 142290 Russia, e-mail kosobr@rambler.ru

ORCID:

Martirosyan Yu.Ts. orcid.org/0000-0001-8825-2381

Martirosyan L.Yu. orcid.org/0000-0003-1769-6377

Kosobryukhov A.A. orcid.org/0000-0001-7453-3123 
The work was performed in the framework of state assignment (No. 0574-2014-0009)

\section{Abstract}

In natural conditions of plant growth, along with changes in the intensity of light during different periods of time, there is a change in the spectral composition of the incident radiation. The ratio between the blue and red spectral regions changes from $\approx 0.50$ for direct radiation of the sun, to $\approx 0.95$ for diffuse solar radiation, depending on the height of the sun and the time of day. The work investigated the effect of light of different spectral composition on the functional characteristics of the photosynthetic apparatus of potato plants (Solanum tuberosum L.) of the Zhukovsky Early variety, grown by aeroponics in two vegetation chambers of a phytotron using LEDs sources with preferential irradiation of plants with blue light (LEDs BL, $\lambda_{\max }=470 \mathrm{~nm}$ ) or red light (LEDs RL, $\lambda_{\max }=660 \mathrm{~nm}$ ) of the spectral range of photosynthetically active radiation (PAR). With a total PAR intensity of $400 \pm 28 \mu \mathrm{mol} \cdot \mathrm{m}^{-2} \cdot \mathrm{s}^{-1}$, the proportion of blue light was $293.6 \mu \mathrm{mol} \cdot \mathrm{m}^{-2} \cdot \mathrm{s}^{-1}$ (chamber 1), and of red light it was $262.0 \mu \mathrm{mol} \cdot \mathrm{m}^{-2} \cdot \mathrm{s}^{-1}$ (chamber 2). As a result, the ratio BL/RL (when comparing the intensities of radiation in the two chambers of the phytotron) was about 0.7. The measurements were carried out on plants grown for a long time under irradiation in the PAR rang with the predominant blue $(\mathrm{PAR}+\mathrm{BL})$ or red light $(\mathrm{PAR}+\mathrm{RL})$. The dynamics of photosynthetic indexes were investigated $0,1,2$, and 3 hours after the light regime changed from PAR + RL to PAR + $\mathrm{BL}$ or from PAR $+\mathrm{BL}$ to PAR $+\mathrm{RL}$. When plants were irradiated with a larger share of the red light PAR spectrum (PAR + RL), a lower rate of photosynthesis was observed compared to plants grown with PAR $+\mathrm{BL}$, both at $400 \mu \mathrm{mol} \cdot \mathrm{m}^{-2} \cdot \mathrm{s}^{-1}$ and at saturating light intensity $\left(1200 \mu \mathrm{mol} \cdot \mathrm{m}^{-2} \cdot \mathrm{s}^{-1}\right)$. A change in the PAR + RL spectral mode for PAR + BL resulted in an increase in the rate of photosynthesis, a slight increase in the effective quantum yield and non-photochemical quenching. When the light mode changed from PAR + BL to PAR + RL, photosynthesis rate, electron transport speed, non-photochemical quenching decreased compared to plants irradiated with PAR + $\mathrm{BL}$, but no change was observed in the maximum and effective quantum yield. The specific effects of blue and red light on the activity of light reactions in photosynthesis and the rate of photosynthesis in changing spectral composition after long-term plant exposure to environmental factors, which we detected for the first time in this work, make it possible to better understand the nature of plant adaptation in natural growth conditions. In plant growing with LED lighting, this allows directional use of LED emitters of different spectral composition, given the duration of predominantly blue or red irradiation.

Keywords: spectral regime, photosynthetic apparatus, rate of photosynthesis, electron transport, non-photochemical quenching, light-emitting diodes, Solanum tuberosum L., potato.

\section{Научные собрания}

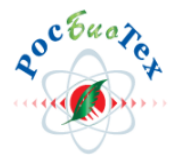

\section{РосБиоТех-2019}

XIII Международный биотехнологический Форум-Выставка «РосБиоТех-2019», ставший традиционным, пройдет в Московском государственном университете пищевых производств 2426 апреля 2019 года.

Мероприятие объединит площадку делового и научного форума, интересную выставочную экспозицию, а также конкурсную арену, где молодые российские и зарубежные ученые представят свои научные достижения.

\section{Тематические направления:}

- биоэнергетика, биотопливо;

- медицинская биотехнология;

- промышленная биотехнология;

- сельскохозяйственная биотехнология; пищевая биотехнология;

- морская биотехнология;

- лесная биотехнология;

- природоохранная (экологическая) биотехнология; экологическая безопасность;

- геронтология;

- «зеленая экономика» - качество жизни и активное долголетие

Контакты и информация: http://www.rosbiotech.com, http://www.salonexpo.ruwww.salonexpo.ru e-mail: info@rosbiotech.com 